\title{
Plumbagin exhibits an anti-proliferative effect in human osteosarcoma cells by downregulating FHL2 and interfering with Wnt/ $\beta$-catenin signalling
}

\author{
YUAN-LIANG XUE ${ }^{1 *}$, XIANG-QI MENG ${ }^{2 *}$, LONG-JUN MA $^{3}$ and ZHEN YUAN ${ }^{4}$ \\ ${ }^{1}$ Department of Orthopedics of Clinical College, Shandong University of Traditional Chinese Medicine, Jinan, \\ Shandong 250014; ${ }^{2}$ Department of Orthopedics, Suzhou Hospital of Traditional Chinese Medicine, Suzhou, \\ Jiangsu 215000; ${ }^{3}$ Department of Orthopedics, People's Hospital of Yangxin, Binzhou, Shandong 251800; \\ ${ }^{4}$ Department of Orthopedics, Shandong Provincial Qianfoshan Hospital, Jinan, Shandong 250014, P.R. China
}

Received February 25, 2015; Accepted March 10, 2016

DOI: $10.3892 / \mathrm{ol} .2016 .4725$

\begin{abstract}
Plumbagin, a naphthoquinone constituent of Plumbago zeylanica L. (Plumbaginaceae) is widely used in traditional Chinese medicine as an antifungal, antibacterial and anti-inflammatory agent. Plumbagin is known to exhibit proapoptotic, antiangiogenic and antimetastatic effects in cancer cells. The transcriptional co-factor four and a half LIM domains 2 (FHL2) is a multifunctional adaptor protein that is involved in the regulation of gene expression, signal transduction and cell proliferation and differentiation, and also acts as a tumor suppressor or oncoprotein depending on the tissue microenvironment. The present study investigated the effect of plumbagin on FHL2 expression, Wnt/ $\beta$-catenin signalling and its anti-proliferative activity in various human osteosarcoma cell lines, including SaOS2, MG63, HOS and U2OS. The cells were exposed to plumbagin and the expression of FHL2 was evaluated using western blot analysis. Furthermore, the anti-proliferative effect of plumbagin was evaluated using a 3-(4,5 dimethyl-thiazol-2-yl)-2,5-diphenyltetrazolium bromide assay. In addition, since FHL2 is involved in Wnt/ $\beta$-catenin signaling, the effect of plumbagin on $\beta$-catenin and its primary target genes, including $\mathrm{v}$-myc avian myelocytomatosis viral oncogene homolog (c-Myc) and WNT1 inducible signaling pathway protein-1 (WISP-1), was evaluated using western blot analysis. It was observed that plumbagin suppressed the expression of FHL2 and exhibited significant anti-proliferative activity in osteosarcoma cells. It also attenuated $\mathrm{Wnt} / \beta$-catenin signalling by downregulating $\beta$-catenin and its target genes,
\end{abstract}

Correspondence to: Dr Zhen Yuan, Department of Orthopedics, Shandong Provincial Qianfoshan Hospital, 16766 Jingshi Road, Jinan, Shandong 250014, P.R. China

E-mail: yuanzhen167@gmail.com

*Contributed equally

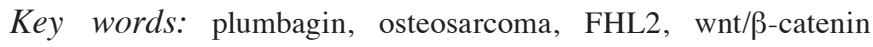
signalling, c-Myc, WISP-1 including c-Myc and WISP-1. In conclusion, plumbagin demonstrated anti-proliferative activity in osteosarcoma cells by downregulating FHL2 and interfering with Wnt/ $\beta$-catenin signalling.

\section{Introduction}

Osteosarcoma, a primary bone sarcoma, is generally observed in children and adolescents and comprises $~ 5 \%$ of pediatric tumors and $20 \%$ of bone tumors with a predominance in males (1). The tumour commonly originates in the metaphyseal regions of the distal femur, proximal humerus and proximal tibia. Osteosarcoma presents with high metastasis that is generally characterized by local invasion to the bone and soft tissue, and it most often affects the lung in distant metastasis (2). Conventional therapeutic approaches for osteosarcoma may cause drug-resistance and yield a variety of side effects, including cardiotoxicity, hearing loss, nephrotoxicity and risk of local relapse (3). An improved understanding of the molecular mechanisms involved in oncogenesis of osteosarcoma may enable identification and development of novel strategies for therapy in this disease.

Several studies have reported the aberrant activation of Wnt signaling in a variety of bone and soft-tissue sarcomas (4-8). Wnt signalling cascades regulate various biological processes, including cell-cycle regulation and stem cell maintenance (9-11), and are also involved in bone development and homeostasis $(12,13)$. The Wnt/ $\beta$-catenin signalling cascade is the best characterized of the Wnt pathways. An accumulation of $\beta$-catenin in the nucleus or cytoplasm of a cell is key for Wnt signal activation, and has been reported in osteosarcoma (14). Upon activation of Wnt signal, $\beta$-catenin translocates to the nucleus and binds to the transcription factors T-cell factor (TCF)/ lymphoid enhancer factor, which activates genes involved in cell proliferation, including v-myc avian myelocytomatosis viral oncogene homolog (c-Myc), mettatoproteinases and cyclin D1 $(15,16)$.

WNT1 inducible signaling pathway protein-1 (WISP-1) has been reported to be significant in the invasion and migration capabilities of osteosarcoma cells. Studies have reported 
that increased WISP-1 expression is associated with tumor stage. WISP-1 enhances the migration of osteosarcoma cells by upregulating the expression of matrix metalloproteinase (MMP)-2 and MMP-9 with increasing tumor stage (17). Four and a half LIM domains protein 2 (FHL-2) is a member of the LIM-only protein family. LIM-domain containing proteins are key in protein-protein interactions in vital cellular processes, including cytoskeletal organization, and have cellular roles as regulators of gene expression, cell adhesion, cell motility and signal transduction (18). Studies also suggest that FHL-2 is involved in various types of cancer, including metastatic melanoma, prostate, breast, lung, colon, gastric and bladder cancer (19-21), and a mechanism by which FHL-2 induces oncogenesis is by binding to $\beta$-catenin (22). However, the effect of FHL-2 on bone cancer tumorigenesis remains unclear. Targeting the Wnt/ $\beta$-catenin signaling pathway may be of important clinical value in osteosarcoma therapy. Recent studies have reported the effective modulation of the $\mathrm{Wnt} / \beta$-catenin signaling pathway by phytochemicals $(23,24)$.

Plumbagin is a naphthoquinone constituent of Plumbago zeylanica L. (Plumbaginaceae) (Fig. 1), and has been used as an antifungal, antibacterial, and anti-inflammatory agent in traditional medicine (25). Plumbagin is known to exhibit proapoptotic (26), antiangiogenic (27) and antimetastatic effects in cancer cells (28). In addition, plumbagin is known to inhibit NF- $\mathrm{KB}$ (29), c-Jun-NH(2)-terminal kinase (30), protein kinase $\mathrm{C} \varepsilon$ (31) and signal transducer and activator of transcription 3 (31). Plumbagin activates glycogen synthase kinase $3 \beta$ by inhibiting its phosphorylation at serine 9 (32), decreases the expression of cyclin D1 (33) and modulates the acetyltransferase activity of p300 protein (34). Consequently, the present study investigated the effect of plumbagin on FHL2 expression in various osteosarcoma cell lines, and it's effect on cell proliferation and Wnt $/ \beta$-catenin signaling in these cells.

\section{Materials and methods}

Cell culture. Cancer cell lines derived from various human osteosarcoma tumors (human p53-deficient SaOS2, p53 mutant MG63 and human osteosarcoma HOS and U2OS cells) (35) were obtained from American Type Culture Collection (Manassas, VA, USA). The cells were cultured according to the company's protocol in Dulbecco's Modified Eagle Medium (Gibco ${ }^{\circledR}$; Thermo Fisher Scientific, Inc., Waltham, MA, USA) containing $10 \%$ heat inactivated fetal calf serum (Sigma-Aldrich, St. Louis, MO, USA), 1\% L-glutamine (Sigma-Aldrich) and penicillin/streptomycin $(10,000 \mathrm{U} / \mathrm{ml}$; Sigma-Aldrich) at $37^{\circ} \mathrm{C}$ in a humidified atmosphere with $5 \%$ $\mathrm{CO}_{2}$.

Cell proliferation assay. The effect of plumbagin on the proliferation of human osteosarcoma SaOS2, MG63, HOS and U2OS cells was assessed using a 3-(4,5 dimethyl-thiazol-2-yl)-2,5-diphenyltetrazolium bromide (MTT) assay. Briefly, the cells were seeded into 96-well plates (Thermo Fisher Scientific, Inc.) at a density of $5-8 \times 10^{3}$ cells/well. The cells were subsequently treated with various concentration of plumbagin $(0,10,20$ or $40 \mu \mathrm{g}$; Sigma-Aldrich) or dimethyl sulfoxide (DMSO; vehicle

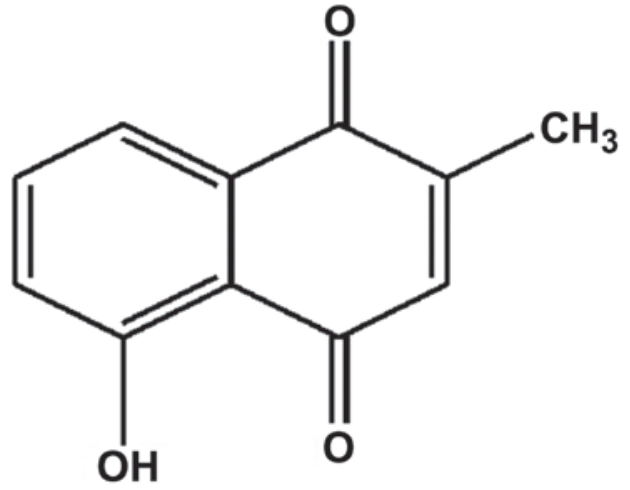

Figure 1. Chemical structure of plumbagin. Molecular formula, 5-hydroxy2-methyl-1,4-naphthoquinone; molecular weight, 188.18.

control; Sigma-Aldrich) for $72 \mathrm{~h}$ at $37^{\circ} \mathrm{C}$. Following treatment, $100 \mu \mathrm{l}$ MTT ( $1 \mathrm{mg} / \mathrm{ml}$; Sigma-Aldrich) was added to each well to analyze cell growth. DMSO was added following an incubation period of $4 \mathrm{~h}$ at $37^{\circ} \mathrm{C}$, to lyse the cells and dissolve the purple formazan crystals that had formed. Absorbance of the formed formazan product was determined at $\lambda$ max of $595 \mathrm{~nm}$ using a fluorescence spectrophotometer (HTS 7000 Reader; MTX Lab Systems Inc., Vienna, VA, USA). By plotting the percentage survival of cells against the concentration of plumbagin, the half maximal inhibitory concentration $\left(\mathrm{IC}_{50}\right)$ values were obtained from the sigmoidal curve.

Western blot analysis. The human osteosarcoma SaOS2, MG63, HOS and U2OS cells were exposed to various concentrations of plumbagin $(10,20$ and $40 \mu \mathrm{g} / \mathrm{ml})$ or DMSO (vehicle control) at $37^{\circ} \mathrm{C}$ for $24 \mathrm{~h}$, and following incubation the cells were lysed. The cells were treated with ice-cold hypotonic lysis buffer (10 mM HEPES, $\mathrm{pH} 7.9 ; 1.5 \mathrm{mM} \mathrm{MgCl}$, $0.2 \mathrm{mM} \mathrm{KCl} ; 0.5 \mathrm{mM}$ dithiothreitol; $0.2 \mathrm{mM}$ phenylmethylsulfonylfluoride; Sigma-Aldrich), vortexed for $2 \mathrm{~min}$ and were centrifuged for 10-15 min at 12,000 rpm, followed by collection of the supernatants and assaying for protein concentration using Lowry's method (36-38) using a Pierce Modified Lowry Protein Assay kit (Thermo Fisher Scientific, Inc.). The proteins $(40-45 \mu \mathrm{g})$ were then subjected to $12 \%$ sodium dodecyl sulfate polyacrylamide gel-electrophoresis. $\beta$-actin was used as a loading control. The gels were transferred onto polyvinylidene difluoride membranes by electro-blotting and membranes were treated for $1 \mathrm{~h}$ with blocking buffer (5\% non-fat dry milk) at room temperature. Subsequently, the membranes were incubated with the following primary antibodies overnight at $4^{\circ} \mathrm{C}$, at dilutions according to the manufacturer's protocol: Rabbit polyclonal anti-FHL2 (dilution, 1:1,000; catalog no., ab12327; Abcam, Cambridge, MA, USA), rabbit monoclonal anti- $\beta$-catenin (dilution, 1:1,000; catalog no., 8480; Cell Signaling Technology, Inc., Danvers, MA, USA), rabbit monoclonal anti- $\beta$-actin (dilution, 1:1,000; catalog no., 4970; Cell Signaling Technology, Inc.), rabbit monoclonal anti-c-Myc (dilution, 1:1,000; catalog no., 13987; Cell Signaling Technology, Inc.), and rabbit polyclonal anti-WISP1 (dilution, 1:1,000; catalog no., Santa Cruz Biotechnology, Inc., Dallas, TX, USA). After incubation with primary antibodies, the membranes were wahsed 
A

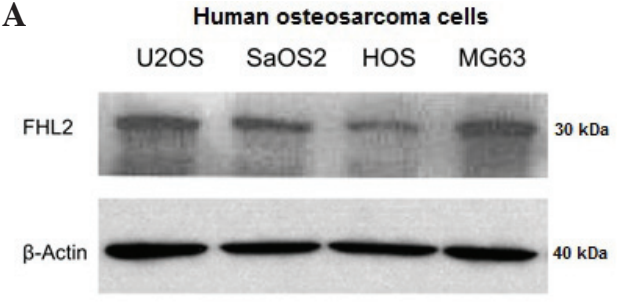

$\mathbf{B}$

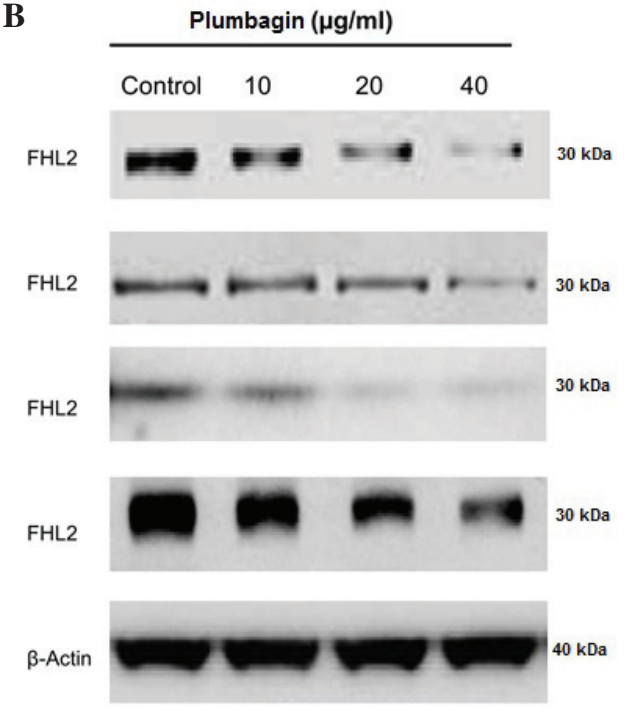

Figure 2. (A) Normal expression of FHL2 in various human osteosarcoma cells. (B) Effect of plumbagin $(10,20,40 \mu \mathrm{g} / \mathrm{ml})$ on the expression of FHL2 in human osteosarcoma cells. FHL2, four and a half LIM domains protein 2; control, dimethyl sulfoxide.

with TBST 3-4 times and incubated with goat anti-rabbit polyclonal horseradish peroxidase-conjugated secondary antibody (dilution, 10,000; catalog no., ab6721; Abcam) for $1 \mathrm{~h}$ at room temperature. The membranes were washed three times for $5 \mathrm{~min}$ with phosphate-buffered saline with Tween 20 (Thermo Fisher Scientific, Inc.) and bands were visualized using hydrogen peroxidase-chemiluminescent detection kit (Frontier Laboratories, Koriyama, Japan) using Luminescent Image Analyzer LAS-3000 (Fujifilm Corp., Tokyo, Japan).

Statistical analysis. The experiments were performed three times and data are expressed as the mean \pm standard deviation. SPSS version 17 (SPSS, Inc., Chicago, IL, USA) was used to perform statistical analyses. Results were analyzed using Student's t-test. $\mathrm{P}<0.05$ was considered to indicate a statistically significant difference.

\section{Results}

Overexpression of FHL2 in osteosarcoma cells. The expression of FHL2 in osteosarcoma U2OS, HOS, SaOS2 and MG63 cells was determined by western blot analysis. A single band was observed at the predicted molecular weight in all osteosarcoma cells (Fig. 2A). FHL2 expressions in HOS and SaOS2 cells were decreased compared to the expressions observed in MG63 and U2OS cells. These results suggest that there is expression of FHL2 in certain human osteosarcoma cells in vitro.
Plumbagin downregulates the expression of FHL2 in human osteosarcoma cells. The osteosarcoma cells were exposed to various concentrations of plumbagin $(10,20,40 \mu \mathrm{g} / \mathrm{ml})$ for $24 \mathrm{~h}$. It was observed that plumbagin inhibited the expression of FHL2 in a dose-dependent manner in MG63, U2OS and $\mathrm{SaOS} 2$ cells compared with the control (DMSO) (Fig. 2B). Plumbagin also effectively inhibited the expression of FHL-2 in HOS cells, which exhibited mild expressions of FHL2.

Effect of plumbagin on cell proliferation. The anti-proliferative effect of plumbagin on U2OS (Fig. 3A), SaOS2 (Fig. 3B), HOS (Fig. 3C) and MG-63 (Fig. 3D) cells was evaluated by MTT assay. A $72 \mathrm{~h}$ exposure of U2OS, SaOS2, HOS and MG-63 cells to various concentrations of plumbagin $(0,10,20$ and $40 \mu \mathrm{g} / \mathrm{ml}$ ) induced a dose-dependent inhibition in cell proliferation. The effect was clearer in U2OS, SaOS2 and MG-63 cells compared with HOS cells.

Effect of plumbagin on Wnt/ $\beta$-catenin signaling. Similarly to the plumbagin-induced downregulation of FHL2, the nuclear translocation of $\beta$-catenin was also attenuated dose-dependently in cells treated with plumbagin (Fig. 4A). To additionally confirm the effect of FHL2 inhibition on Wnt signaling, the expression of WISP-1 and c-Myc, which are $\mathrm{Wnt} / \beta$-catenin-target genes, in cells treated with various concentrations of plumbagin $(10,20$ and $40 \mu \mathrm{g} / \mathrm{ml})$ were assessed. Plumbagin dose-dependently inhibited the expressions of WISP-1 and c-Myc (Fig. 4B and C).

\section{Discussion}

In the present study, the effect of plumbagin on the expression of FHL 2 and Wnt/ $\beta$-catenin signaling were assessed. An altered FHL 2 expression was observed in osteosarcoma cells treated with plumbagin, similarly to the results reported in previous studies $(35,39)$. In addition, previous studies have demonstrated that FHL2 gene expression in human soft tissue cancers is variable depending on the cell type; FHL2 was revealed to be overexpressed in breast cancer (40), glioma (41), lung cancer (42), colon carcinoma (20) and gastrointestinal cancer (43) cells compared with cells from normal tissue.

FHL2 has been reported to effectively interact with numerous transcription factors, including androgen receptor, activator protein 1, cAMP response element-binding (CREB) protein, SKI proto-oncogene and $\beta$-catenin $(43,44-46)$, and FHL2 functions as a coactivator or corepressor, depending on the cell type and the promoter that is present $(22,46)$. Furthermore, FHL2 binds with various transcription factors concurrently and participates in multiprotein complex assemblies $(47,48)$. As a coactivator of $\beta$-catenin it cooperates with CREB-binding protein/p300 to enhance transcription driven by the $\beta$-catenin/TCF complex $(46,47)$.

The present study focused on the effect of plumbagin on Wnt/ $\beta$-catenin signaling cascade, since FHL2 interacts with this pathway in various cells $(22,49)$, including osteoblast progenitor cells (46). In addition, dysregulation of the pathway has been reported in osteosarcoma cells $(14,50)$. In the present study, plumbagin dose-dependently reduced the expression of FHL2 in osteosarcoma U2OS, HOS, SaOS2 and MG63 cells 

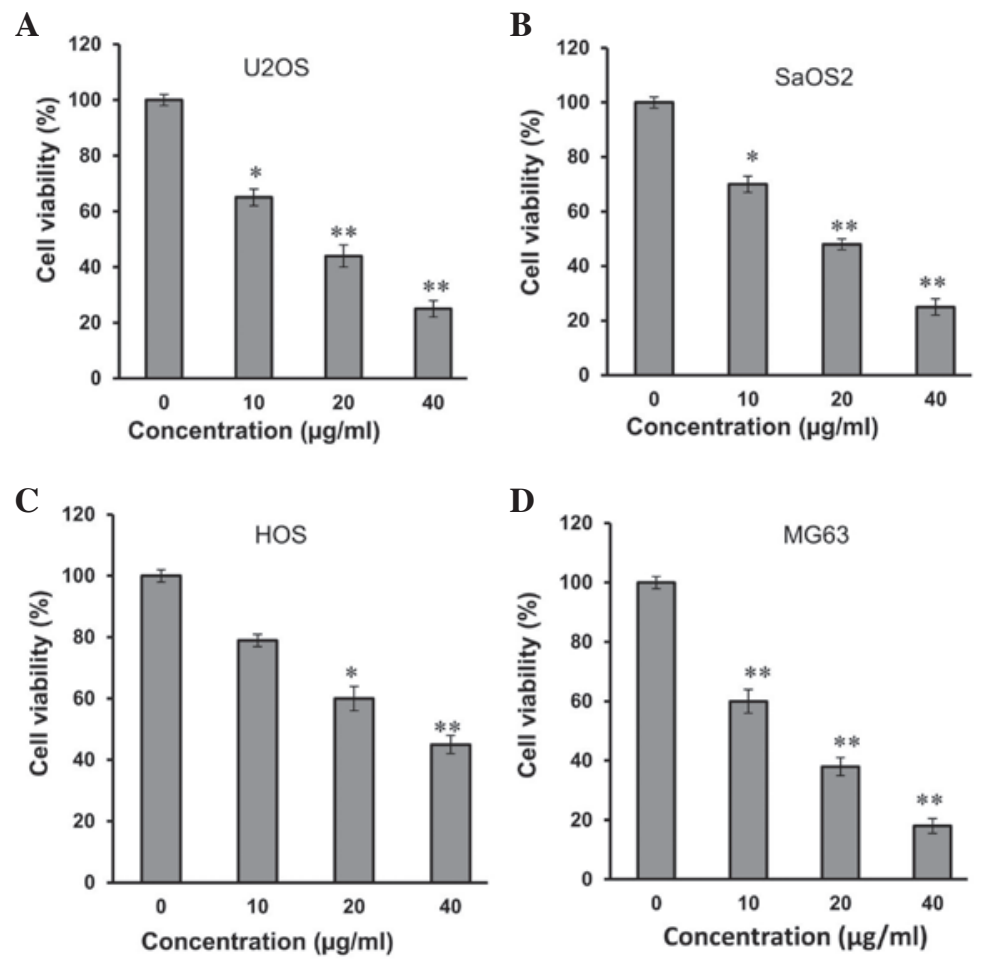

Figure 3. Anti-proliferative effect of plumbagin in human osteosarcoma (A) U2OS, (B) SaOS2, (C) HOS and (D) MG-63 cells at various concentrations. Data is represented as the mean \pm standard deviation of three different experiments. ${ }^{*} \mathrm{P}<0.05,{ }^{* * *} \mathrm{P}<0.01$ vs. control.
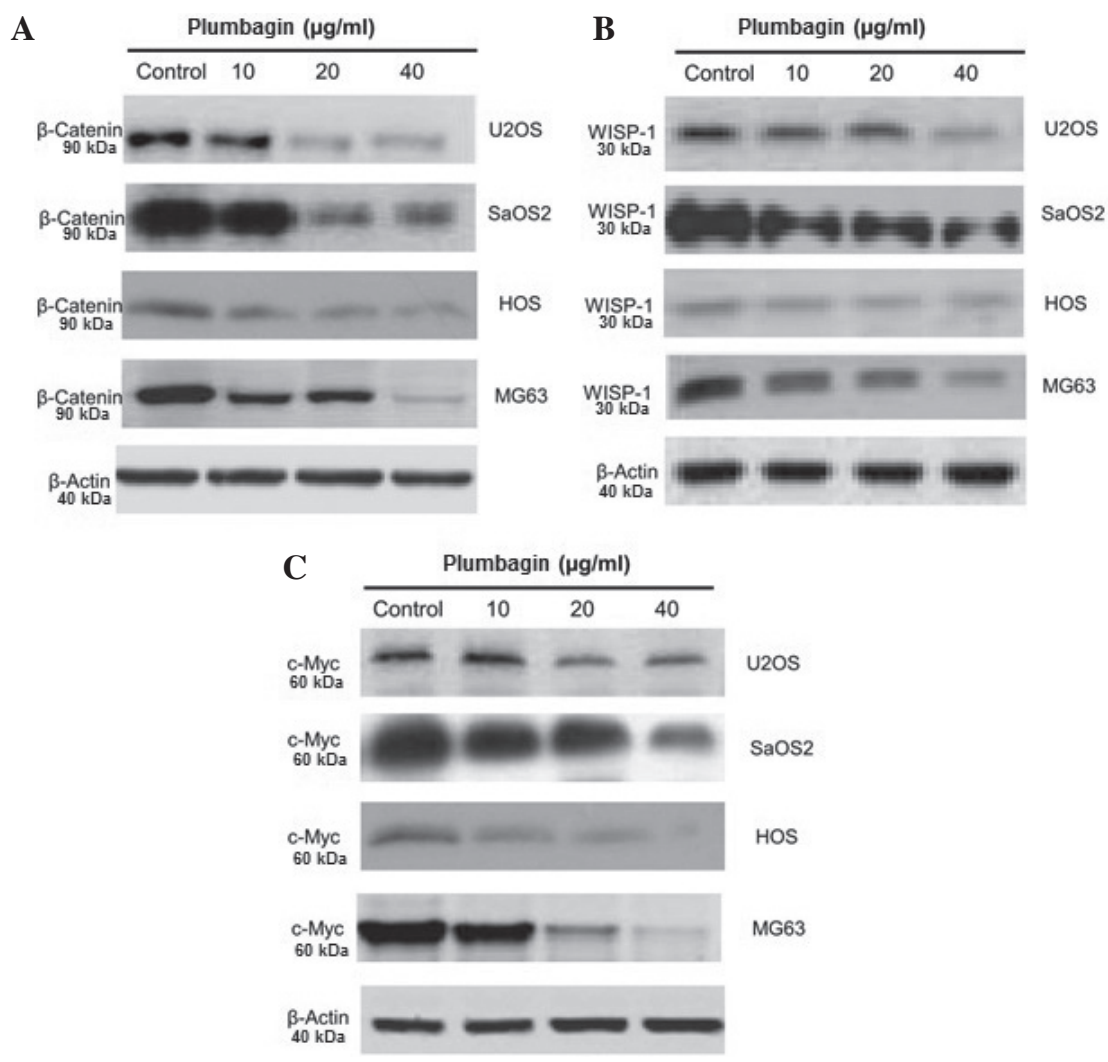

Figure 4. Effect of plumbagin on the expression of (A) $\beta$-catenin, (B) c-Myc and (C) WIST-1 in human osteosarcoma U2OS, SaOS2, HOS and MG63 cells. c-Myc, v-myc avian myelocytomatosis viral oncogene homolog; WIST-1, WNT1 inducible signaling pathway protein-1; control, dimethyl sulfoxide.

and reduced the proliferation of the cells. Plumbagin-induced inhibition of FHL2 in the osteosarcoma cells also led to a reduction of $\beta$-catenin translocation into the nucleus of these cells, which was evidenced by the reduction in the expression of c-Myc, a key target protein and onco-protein. The expression of WISP-1, a direct Wnt/ $\beta$-catenin target gene (51), was 
also effectively downregulated by plumbagin in the present study. A dose-dependent decrease in the expression of c-Myc and WIST-1 was observed. Additionally, the decrease in the expressions of c-Myc and WISP was similar to the expression levels of FHL2 in U2OS, SaOS2 and MG63 cells. By contrast, HOS cells expressed a lower amount of FHL2 and exhibited almost insignificant levels of FHL2 following plumbagin exposure and negligible expression of c-Myc and WISP-1. The underlying cause of this requires additional investigation.

Overall in the present study, plumbagin significantly reduced the proliferation of osteosarcoma cells via the inhibition of Wnt/ $\beta$-catenin signalling by downregulating the Wnt co-regulator FHL2, an oncoprotein in osteosarcoma cells. Therefore, following additional preclinical and clinical evaluations, plumbagin may be effectively used in osteosarcoma therapeutics.

\section{References}

1. Ottaviani G and Jaffe N: The epidemiology of osteosarcoma. In: Pediatric and Adolescent Osteosarcoma. Jaffe N, Bruland OS and Bielack S (eds). Springer: New York, NY, pp3-13, 2009.

2. Guijarro MV, Ghivizzani SC and Gibbs CP: Animal models in osteosarcoma. Front Oncol 4: 189, 2014.

3. Luetke A, Meyers PA, Lewis I and Juergens H: Osteosarcoma treatment-where do we stand? A state of the art review. Cancer Treat Rev 40: 523-532, 2014.

4. Weeraratna AT, Jiang Y, Hostetter G, Rosenblatt K, Duray P, Bittner M and Trent JM: Wnt5a signaling directly affects cell motility and invasion of metastatic melanoma. Cancer Cell 1: 279-288, 2002

5. Wissmann C, Wild PJ, Kaiser S, Roepcke S, Stoehr R, Woenckhaus M, Kristiansen G, Hsieh JC, Hofstaedter F, Hartmann A, et al: WIF-1, a component of the Wnt pathway, is down-regulated in prostate, breast, lung and bladder cancer. J Pathol 201: 204-212, 2003.

6. Hoang BH, Kubo T, Healey JH, Yang R, Nathan SS, Kolb EA, Mazza B, Meyers PA and Gorlick R: Dickkopf 3 inhibits invasion and motility of SaOS-2 osteosarcoma cells by modulating the Wnt-beta-catenin pathway. Cancer Res 64: 2734-2739, 2004.

7. Barker $\mathrm{N}$ and Clevers $\mathrm{H}$ : Mining the Wnt pathway for cancer therapeutics. Nat Rev Drug Discov 5: 997-1014, 2006.

8. Lin YC, You L, Xu Z, He B, Mikami I, Thung E, Chou J, Kuchenbecker K, Kim J, Raz D, et al: Wnt signaling activation and WIF-1 silencing in nasopharyngeal cancer cell lines. Biochem Biophys Res Commun 341: 635-640, 2006.

9. Huelsken $J$ and Birchmeier W: New aspects of Wnt signaling pathways in higher vertebrates. Curr Opin Genet Dev 11: 547-553, 2001

10. Mlodzik M: Planar cell polarization: Do the same mechanisms regulate Drosophila tissue polarity and vertebrate gastrulation? Trends Genet 18: 564-571, 2002.

11. Clevers H: Wnt/beta-catenin signaling in development and disease. Cell 127: 469-480, 2006.

12. Westendorf JJ, Kahler RA and Schroeder TM: Wnt signaling in osteoblasts and bone diseases. Gene 341: 19-39, 2004.

13. Rawadi G and Roman-Roman S: Wnt signalling pathway: A new target for the treatment of osteoporosis. Expert Opin Ther Targets 9: 1063-1077, 2005.

14. Haydon RC, Deyrup A, Ishikawa A, Heck R, Jiang W, Zhou L, Feng T, King D, Cheng H, Breyer B, et al: Cytoplasmic and/or nuclear accumulation of the beta-catenin protein is a frequent event in human osteosarcoma. Int J Cancer 102: 338-342, 2002.

15. Reya $\mathrm{T}$ and Clevers $\mathrm{H}$ : Wnt signalling in stem cells and cancer. Nature 434: 843-850, 2005.

16. Espada J, Calvo MB, Diaz-Prado S and Medina V: Wnt signaling and cancer stem cells. Clin Transl Oncol 11: 411-427, 2009.

17. Wu CL, Tsai HC, Chen ZW, Wu CM, Li TM, Fong YC and Tang CH: Ras activation mediates WISP-1-induced increases in cell motility and matrix metalloproteinase expression in human osteosarcoma. Cell Signal 25: 2812-2822, 2013.

18. Kadrmas JL and Beckerle MC: The LIM domain: From the cytoskeleton to the nucleus. Nat Rev Mol Cell Biol 5: 920-931, 2004.
19. Gabriel B, Fischer DC, Orlowska-Volk M, zur Hausen A, Schüle R, Müller JM and Hasenburg A: Expression of the transcriptional coregulator FHL2 in human breast cancer: A clinicopathologic study. J Soc Gynecol Investig 13: 69-75, 2006.

20. Wang J, Yang Y, Xia HH, Gu Q, Lin MC, Jiang B, Peng Y, Li G, An X, Zhang Y, et al: Suppression of FHL2 expression induces cell differentiation and inhibits gastric and colon carcinogenesis. Gastroenterology 132: 1066-1076, 2007.

21. Amann T, Egle Y, Bosserhoff AK and Hellerbrand C: FHL2 suppresses growth and differentiation of the colon cancer cell line HT-29. Oncol Rep 23: 1669-1674, 2010.

22. Martin B, Schneider R, Janetzky S, Waibler Z, Pandur P, Kühl M, Behrens J, von der Mark K, Starzinski-Powitz A and Wixler V: The LIM only protein FHL2 interacts with beta-catenin and promotes differentiation of mouse myoblasts. J Cell Biol 159: 113-122, 2002.

23. Zhang J, Cao H, Zhang B, Cao H, Xu X, Ruan H, Yi T, Tan L, Qu R, Song G, et al: Berberine potently attenuates intestinal polyps growth in ApcMin mice and familial adenomatous polyposis patients through inhibition of Wnt signalling. J Cell Mol Med 17: 1484-1493, 2013.

24. Kim JH, Kim YH, Song GY, Kim DE, Jeong YJ, Liu KH, Chung YH and Oh S: Ursolic acid and its natural derivative corosolic acid suppress the proliferation of APC-mutated colon cancer cells through promotion of $\beta$-catenin degradation. Food Chem Toxicol 67: 87-95, 2014.

25. Padhye S, Dandawate P, Yusufi M, Ahmad A and Sarkar FH: Perspectives on medicinal properties of plumbagin and its analogs. Med Res Rev 32: 1131-1158, 2012.

26. Xu TP, Shen H, Liu LX and Shu YQ: Plumbagin from Plumbago zeylanica $\mathrm{L}$ induces apoptosis in human non-small cell lung cancer cell lines through NF-kB Inactivation. Asian Pac J Cancer Prev 14: 2325-2331, 2013.

27. Sinha S, Pal K, Elkhanany A, Dutta S, Cao Y, Mondal G, Iyer S, Somasundaram V, Couch FJ, Shridhar V, et al: Plumbagin inhibits tumorigenesis and angiogenesis of ovarian cancer cells in vivo. Int J Cancer 132: 1201-1212, 2013.

28. Hafeez BB, Zhong W, Fischer JW, Mustafa A, Shi X, Meske L, Hong H, Cai W, Havighurst T, Kim K and Verma AK: Plumbagin, a medicinal plant (Plumbago zeylanica)-derived 1,4-naphthoquinone, inhibits growth and metastasis of human prostate cancer PC-3M-luciferase cells in an orthotopic xenograft mouse model. Mol Oncol 7: 428-439, 2013.

29. Ahmad A, Banerjee S, Wang Z, Kong D and Sarkar FH: Plumbagin-induced apoptosis of human breast cancer cells is mediated by inactivation of NF-kappaB and Bcl-2. J Cell Biochem 105: 1461-1471, 2008

30. Hsu YL, Cho CY, Kuo PL, Huang YT and Lin CC: Plumbagin (5-hydroxy-2-methyl-1,4-naphthoquinone) induces apoptosis and cell cycle arrest in A549 cells through p53 accumulation via c-Jun NH2-terminal kinase-mediated phosphorylation at serine 15 in vitro and in vivo. J Pharmacol Exp Ther 318: 484-494, 2006.

31. Hafeez BB, Zhong W, Mustafa A, Fischer JW, Witkowsky O and Verma AK: Plumbagin inhibits prostate cancer development in TRAMP mice via targeting PKC $\varepsilon$, Stat 3 and neuroendocrine markers. Carcinogenesis 33: 2586-2592, 2012.

32. Kuo PL, Hsu YL and Cho CY: Plumbagin induces G2-M arrest and autophagy by inhibiting the AKT/mammalian target of rapamycin pathway in breast cancer cells. Mol Cancer Ther 5: 3209-3221, 2006

33. Gomathinayagam R, Sowmyalakshmi S, Mardhatillah F, Kumar R, Akbarsha MA and Damodaran C: Anticancer mechanism of plumbagin, a natural compound, on non-small cell lung cancer cells. Anticancer Res 28: 785-792, 2008.

34. Ravindra KC, Selvi BR, Arif M, Reddy BA, Thanuja GR, Agrawal S, Pradhan SK, Nagashayana N, Dasgupta D and Kundu TK: Inhibition of lysine acetyltransferase KAT3B/p300 activity by a naturally occurring hydroxynaphthoquinone, plumbagin. J Biol Chem 284: 24453-24464, 2009.

35. Khanna C, Prehn J, Yeung C, Caylor J, Tsokos M and Helman L: An orthotopic model of murine osteosarcoma with clonally related variants differing in pulmonary metastatic potential. Clin Exp Metastasis 18: 261-271, 2000.

36. Davies EM: Protein assays: A review of common techniques. Am Biotech Lab 6: 28-37, 1988

37. Legler G, Müller-Platz CM, Mentges-Hettkamp M, Pflieger G and Julich E: On the chemical basis of the Lowry protein determination. Anal Biochem 150: 278-287, 1985.

38. Lowry OH, Rosebrough NJ, Farr AL and Randall RJ: Protein measurement with the Folin Phenol Reagent. J Biol Chem 193: 267-275, 1951. 
39. Jaffe N: Osteosarcoma: Review of the past, impact on the future. The American experience. Cancer Treat Res 152: 239-262, 2009.

40. Martin BT, Kleiber K, Wixler V, Raab M,Zimmer B, Kaufmann M and Strebhardt K: FHL2 regulates cell cycle-dependent and doxorubicin-induced $\mathrm{p} 21 \mathrm{Cip1} / \mathrm{Waf} 1$ expression in breast cancer cells. Cell Cycle 6: 1779-1788, 2007.

41. Li M, Wang J, Ng SS, Chan CY, Chen AC, Xia HP, Yew DT, Wong BC, ChenZ, Kung HF and Lin MC: The four-and-a-half-LIM protein 2 (FHL2) is overexpressed in gliomas and associated with oncogenic activities. Glia 56: 1328-1338, 2008.

42. Tanahashi H and Tabira T: Alzheimer's disease-associated presenilin 2 interacts with DRAL, an LIM-domain protein. Hum Mol Genet 9: 2281-2289, 2000.

43. Muller JM, Isele U, Metzger E, Rempel A, Moser M, Pscherer A, Breyer T, Holubarsch C, Buettner R and Schüle R: FHL2, a novel tissue-specific coactivator of the androgen receptor. EMBO J 19: 359-369, 2000

44. Fimia GM, De Cesare D and Sassone-Corsi P: A family of LIM-only transcriptional coactivators: Tissue-specific expression and selective activation of CREB and CREM. Mol Cell Biol 20: 8613-8622, 2000.

45. Morlon A and Sassone-Corsi P: The LIM-only protein FHL2 is a serum-inducible transcriptional coactivator of AP-1. Proc Natl Acad Sci USA 100: 3977-3982, 2003.
46. Wei Y, Renard CA, Labalette C, Wu Y, Lévy L, Neuveut C, Prieur X, Flajolet M, Prigent $\mathrm{S}$ and Buendia MA: Identification of the LIM protein FHL2 as a coactivator of beta-catenin. J Biol Chem 278: 5188-5194, 2003.

47. Labalette C, Renard CA, Neuveut C, Buendia MA and Wei Y: Interaction and functional cooperation between the LIM protein FHL2, CBP/p300 and beta-catenin. Mol Cell Biol 24: 10689-10702, 2004.

48. Yang Y, Hou H, Haller EM, Nicosia SV and Bai W: Suppression of FOXO1 activity by FHL2 through SIRT1-mediated deacetylation. EMBO J 24: 1021-1032, 2005.

49. Hamidouche Z, Haÿ E, Vaudin P, Charbord P, Schüle R, Marie PJ and Fromigué O: FHL2 mediates dexamethasone-induced mesenchymal cell differentiation into osteoblasts by activating Wnt/beta-catenin signaling-dependent Runx2 expression. FASEB J 22: 3813-3822, 2008.

50. Entz-Werle N, Lavaux T, Metzger N, Stoetzel C, Lasthaus C, Marec P, Kalifa C, Brugieres L, Pacquement H, Schmitt C, et al: Involvement of MET/TWIST/APC combination or the potential role of ossification factors in pediatric high-grade osteosarcoma oncogenesis. Neoplasia 9: 678-688, 2007.

51. Nusse R: Wnt signaling in disease and in development. Cell Res 15: 28-32, 2005. 